\title{
An Intervention Programme to Facilitate the Preschool Transition in Mexico
}

\section{Programa de Intervención para facilitar la Transición al Primer año de Primaria}

DOl: https://doi.org/10.32870/dse.v0i21.664

\author{
Miguel Ángel Urbina-García*
}

\begin{abstract}
Over the last two decades there has been a growing interest in promoting a smooth transition to first grade of primary school given the potential long-term effects a smooth transition can have in preschool children at academic and personal level. Research shows that psycho-educational interventions help improve children's academic and personal skills, lessening the effects of this challenging change. This study, sought to explore the efficacy of an intervention programme to facilitate this transition in Mexico City, by using a quasi-experimental cross sectional design. Statistical significant differences were found in children' skills in pre and post-tests in the experimental group but no in the control group as well as in teachers' use of transition practices. Implications for policy and practice are discussed.
\end{abstract}

Key Words: Preschool Transition - Intervention Programme - Primary School Transition - Mexican Children - Teachers'Transition Practices.

\section{Resumen}

Durante las últimas dos décadas ha habido un creciente interés en facilitar la transición al primer año de primaria, dados los posibles efectos a largo plazo que puede tener este cambio en niños de preescolar a nivel académico y personal. Las investigaciones muestran que las intervenciones psico-educativas ayudan a mejorar estas habilidades en los niños, disminuyendo los efectos de este difícil cambio. Este estudio exploró la eficacia de un programa de intervención para facilitar esta transición en la ciudad de México mediante un estudio transversal y cuasi-experimental. Se encontraron diferencias estadísticamente significativas en la pre-prueba y la post-prueba en el grupo experimental pero no en el grupo control, así como en el uso de prácticas de transición de los maestros. Se analizan las aplicaciones para políticas y práctica se discuten.

Palabras Clave: transición del preescolar - programa de intervención - transición a la primaria - niños mexicanos - prácticas educativas.

* Ph.D. in Educational Psychology (University of York, United Kingdom). Lines of research: Transition to Primary School, Children's Wellbeing, Emotional Development in Children Aged 0 to 7, Happiness in Children, Parental Practices, Listening to the Voices of Children Aged 3 to 7. Lecturer on Early Childhood Studies and Director of the Post-graduate program on Education, University of Hull, United Kingdom. M.Urbina-Garcia@hull.ac.uk 


\section{Introduction}

Research on the preschool transition to first grade has received a great deal of attention in the last two decades which has prompted international researchers to explore a number of variables involved in this challenging change in children starting primary school (Kagan \& Neuman, 2013). Going from preschool to first grade, poses new challenges to children which they have to face including a new environment, relationships, teachers and rules which have been found to have an important impact on their attitudes and roles (Fabian \& Dunlop, 2005; Perry, Dockett \& Petriwskyj, 2014). However, and whilst there have been some efforts in exploring the effectiveness of transition-related interventions (i.e., mainly in developed economies such as Australia, US, UK, Italy, Hong Kong etc.), it is still unknown how this type of interventions could support teachers, teaching assistants, children and parents during this period of change in developing economies such as Latin American with specific cultural and educational policy-related particularities. Moreover, the positive outcomes of intervention programmes have been widely documented (Ahtola et al., 2011: Morrison, Ponitz \& McClelland, 2010; Schulting, Malone \& Dodge, 2005) showing that interventions are positively associated with a better children's academic performance in first grade, nevertheless such research is influenced by the socio-cultural context of developed economies and thus, limiting our understanding of the impact of this interventions in developing economies. The international literature on interventions has provided a wealth of evidence of positive impact on children, teachers and parents during this transition and which has ultimately, helped children successfully transition to the first grade. For instance, Lee and Gogh (2012) undertook an action-research in Singapore with 14 children aged 5 and 6 . Findings revealed a positive change in children's attitudes toward first grade, as well as reduction in parents' anxiety provoked by this period of change, however the limited number of children included in this study poses challenges in terms of data-generalisation. Berlin, Dunning and Dodge (2011) carried out a four-week summer programme in US to facilitate the transition to kindergarten based on a randomised control trial. Results revealed a better development of social skills for girls but, surprisingly, not for boys. Kindergarten teachers reported that this programme did not appear to have a significant impact on children's efficacy on academic demands, nevertheless, authors reported a significant effect on the ability to adapt to school routines of children participating in this programme. However, this study included only children at risk of academic failure, which does not allow for generalisation of the data. Moreover, in the study by Berlin, Dunning and Dodge (2011), the authors did not include a base-line assessment of the children's cognitive and social domains which did not allow to identify the impact of such programme in these areas.

In Hong Kong Li, Mak, Chan, Chu, Lee and Lam (2013), used a randomised control trial design including 143 families where a play-integrated preparatory programme was implemented. Results indicated a decrease in levels of worry and increased levels of happiness six weeks and 
three months after the intervention in the control and the experimental group. Nevertheless, and while the authors claimed that in order for children to have a smooth transition, children need to develop self-control skills -so they can cope with stressful and anxious situations when transitioning-, such skills, were not measured in the study. Furthermore, authors claimed that the programme served this purpose, however no measure with regard to self-awareness, selfcontrol or self-efficacy was carried out.

Hart (2012) implemented two different programmes to help children behaviourally at-risk transitioning to kindergarten in US preschool centres and evaluated their efficacy. A focus (low intervention) and experimental group (high intervention) were created to implement a fourweek summer programme to support this transition. Results indicated fewer behavioural and academic problems for children in the high intervention programme than in the low intervention. The high intervention group showed better behavioural adaptation during the first year of kindergarten. Parents showed a major involvement in the high intervention group, arguably, having a positive effect in helping children during this period. In line with this, the role of significant adults for children (i.e., parents, teachers and caregivers) has been importantly highlighted in this transition. Giallo, Treyvaud, Matthews and Kienhuis (2010) reported that the implementation of transition programmes (i.e., aimed at providing transition practices, establishing home-school links and fostering children's development) resulted in a higher rate of parents' self-efficacy perception which in turn, led to a greater involvement in their child's education. The authors also concluded that when parents are provided with information regarding this transition, they become more interested and tend to establish a more frequent and active home-school interaction. Parents' involvement in transition activities organised by schools, has been associated with the acquisition of useful transition-related parental practices.

Some studies have suggested that parents can become aware of the importance of the transition process after participating in transition programmes (Carida, 2011, Schulting et al., 2005), which leads to a greater participation in school-related activities with their children. Interestingly, in some studies parents have shown a greater interest in this process and specifically with regard to their child's education (Dockett \& Perry, 2007), whilst in others, this interest and awareness have been related to parents' quest for additional information about how to best support their child (Wildenger \& Mclntyre, 2011). Taken together, these findings provide compelling evidence about the effectiveness of interventions during this period of change, which provide and promote knowledge, awareness and practices for teachers and parents. These studies show how designing and implementing an intervention, can lead to better support children, teachers and parents to successfully transit through this change -and build a sense of community needed for this change. Notably, research shows that this change can be experienced in a smoother way if children, parents, teachers are included in intervention programmes. The constant exchange of information and constant interactions among adults in this process 
is a key element in this transition and is known as bridging (Malsch et al., 2011) which is in fact, one of the principles of the Ecological and Dynamic Model of Transitions proposed by RimKauffman and Pianta (2000), -a model which underpins the present study.

Little is known about the way in which the context of developing economies, shape this transition to primary school and how, intervention programmes must be adapted to cultural practices, values, educational policies, curriculum, etc. The novelty of this study is that this intervention, considered various levels namely school, home, home-school and school-school links (framed by the particularities of the culture of a developing economy), and included children parents and teachers, whilst previous research has focused only on teachers or parents separately in either preschool and/or primary school. Based on research conducted in developed economies, we know that children can greatly benefit from this type of interventions. Similarly, research on parents and teachers, shows that adults can play a key role supporting pre-schoolers during this period of chance. Research focused on interventions, has provided a wealth of evidence regarding essential elements that need to be considered when designing and implementing an educational intervention. Worryingly, most of the research in this respect and its positive findings have been framed by the socio-cultural context of developed economies, whilst to our knowledge, there is no research in preschool transition in developing economies as is the case of Latin America which has been overlooked. This study aims to fill these gaps by designing and implementing intervention programme to facilitate the transition to first grade with Latino families with a view to exploring its efficacy considering the Mexican cultural context. A number of transition activities reported in the international literature were carefully analysed and adapted for the present study considering the Mexican context.

\section{Methods}

\section{Design}

This study followed a quasi-experimental design with a pre-test and post-test for preschool children and teachers. This study was carried out during one academic year in two preschool classrooms (one control and one experimental) from two different public schools to a void datacontamination belonging to a government institution which provides social services to the children of government workers in Mexico City.

\section{Participants}

Each preschool classroom included 20 children $(N=40)$, with their respective classroom teacher and teaching assistant $(N=4)$. Children were in the final year of their preschool education ranging from 5 to 6 years old $(M=5.6)$. The two preschool teachers (PT) reported holding an undergraduate diploma in preschool education whilst both teaching assistants (TA) had vocational training. The researcher fully disclosed the main aims of the study to headteachers to obtain 
permission to also recruit families of the preschool children involved. Forty families were contacted to explain the main aim of this study and accepted to participate in this project signing a consent form. Most of parents were female (85\%) reporting that the highest academic degree was undergraduate degree (80\%) and vocational-training (20\%). Parents' age ranged from 30 to 60 years old $(M=44.67)$.

\section{Groups}

We included two intact groups which had already been formed by the administrator of the schools at the beginning of the academic year, following the normal protocols the Ministry of Education. Two public schools were recruited to have one control group in one school, and one experimental group in another. Mann Whitney $U$ test, revealed no significant differences in either the scores of children's skills (i.e., cognitive, social and fine motor) or teachers' early literacy practices at the beginning of the intervention.

\section{Measures}

Children's skills were assessed by using the Assessment and Evaluation Programming System for Infants and Children (AEPS; Bricker, Betty and Pretti-Frontnczak, 2002) which is a criterionreferenced test to measure children's skills in six different key developmental domains, however only three main domains were included in this study due to their relevance in this transition process (Margetts \& Kienig, 2013) namely cognitive, social and fine motor skills. Children's skills were measured considering a 3-point scale: " $0=$ Does not show the skill"; " $1=$ Inconsistent use of the skill" and " $2=$ Consistent use of the skill". Examples of cognitive skills include: "Identification of numbers/figures". Examples of social skills include: "Showing affect to others" and example of fine motor skills include: "Use of scissors by following geometrical shapes". PT and TAS practices that promote literacy in preschool classrooms -which have been reported to aid in this transition (Berlin, Dunning \& Dodge, 2011), were assessed with a self-report questionnaire developed by the researcher based on the "Inventory of Early Literacy Practices" (Neuman, Copple \& Bredekamp, 2001) including 40 items. Preschool teacher and TA rated the extent to which they use these practices in their everyday routine to promote early literacy skills in pre-schoolers based on a 3-point rating scale: " $0=$ Does not use the practice"; " $1=$ Inconsistent use of the practice" and " $2=$ Consistent use of the practice". Parents' views about the support they provide their child with for this transition, were gathered with three open-ended questions developed by the author for the purposes of this study: a) What factors will you consider for choosing the primary school to which your child will attend?; b) In which way do you support your child in this transition?; c) What have you talked about with your child regarding the primary school? Parents' satisfaction with the intervention was rated with a single-item on a 5 -point scale ( $1=$ Very Dissatisfied to $5=$ Very Satisfied $)$. 


\section{Procedure}

Educational authorities granted permission and the researcher contacted headteachers and parents from both schools to fully explain the main aims of the study. Ethical approval was not required the governmental institution providing the educational service, however personal consent forms were obtained from parents and teachers/TAS. At the beginning of the academic year, a pre-test was carried out to assess children's skills and PT and TAS' practices, whilst using participant observation and direct testing (Taylor, Bogdan \& DeVault, 2015), the researcher assessed children's skills in both classrooms. Preschool teacher and TAS completed a 40-items selfreport questionnaire separately in a room specifically designated by headteachers to avoid data-contamination. The post-test was carried out at the end of the academic year, following the same procedure. At this point, parents' views and overall satisfaction with the programme were gathered. The intervention programme was implemented in the experimental group, whilst the control group received the usual pedagogical activities planned by the preschool teacher.

\section{Intervention}

This evidence-informed transition programme (implemented in the experimental group only), included transition activities which have proven useful to enhance the preschoolers' transition (Claes, 2010; Hedegaard \& Fleer, 2013; Peters et al., 2009), adapting them to the cultural particularities of the city and considering the internal educational policies of the preschool centre. This programme was proactive and intensive, working alongside the PT and TA in the classroom for 6 consecutive months with 3 sessions per week. All activities were mainly led by the PT and TA with minor interventions of the researcher. This intervention comprised a range of activities to help a) develop cognitive skills through activities that promote early literacy; b) promote children's social competence; c) develop fine motor skills; d) promote home-school links (e.g., involving families in this transition intervention) and e) promote school-school links (e.g., visits to the primary school). The intervention programme included:

Collaborative work in classroom: The researcher closely worked with the PT and TA based on a collaborative way whereby emphasis was placed on planning the pedagogical activities that promote cognitive, social and fine motor skills necessary for the transition (Brownell et al., 1997). The inclusion of these pedagogical activities was based on the preschool and first grade curriculum as well as what the literature reported as effective transition activities.

Modelling and teaching key developmental aspects during this transition: The researcher contributed to PT and TAS knowledge of developmental aspects and children's skills during the activities included in the daily routine. The researcher, also modelled the implementation of transition activities -unknown to the teacher-included in the weekly-pedagogical plan of the PT. This approach was adopted given that it has been highlighted as essential in order to help teachers develop new skills and acquire new knowledge regarding child development (Loughran, 2002). 
Improvement of classroom-areas: Working collaboratively, the researcher, the preschool teacher and TA, re-designed the distribution of pedagogical material included in different areas in which the preschool classroom was divided as per curriculum guidelines. New pedagogical material was included in some areas, whilst there was also material that did not correspond to the aim of a given area and thus was reallocated. Changes were carried out in areas such as child's library, pretend play, free-play, science, Lego blocks and literacy area.

School-Home links: The researcher, preschool teacher and TA designed a series of activities whereby parents attended to the preschool classroom three times a week in order to carry out different activities with pre-schoolers such as storytelling, explaining parents' type of jobs and talking about how parents' primary school was like.

Literacy-related activities book: An activities-book was developed by the researcher and the preschool teacher containing 20 different attractive activities focused on the development of early literacy skills appropriate for preschoolers which were given to parents for them to complete during the Easter holidays together with their child. It was emphasised the need to carry out these activities alongside their child.

Teddy's Dairy: A project-based activity led by the PT and TA, resulted in the creation of a dairy -which was taken home every day by a different child. The name "Teddy" was decided by preschoolers by participating in a poll. All the paraphernalia needed for this activity (i.e., tickets, names, posters, labels, adds and so forth) was created by preschoolers in an attempt to provide opportunities to practice and thus enhance their skills. In this dairy, children recorded the activities he/she had done during her/his day after school. Parents were also asked to help their child "write" and produce drawings of the activities she/he had decided to included. Additionally, parents were also asked to help their child by writing the activities their child decided to tell his/ her peers the following day. The following day, there was a time allocated for reading the dairy which was facilitated by the main teacher, where preschoolers exchanged ideas regarding the activities shared by their peers.

School-School Links (Visits to Primary School): Preschoolers alongside the PT and TA, visited the primary school in three different times throughout the intervention ranging from one to two hours-visit, depending on the activities planned.

A) First visit: First grade teachers toured preschoolers around the premises of the primary school. Preschoolers were introduced to different first grade teachers by visiting their classrooms and meeting first grade students. Play-based activities were facilitated by one first grade teacher and carried out in the playground of the primary school.

B) Second visit: preschoolers were taken on a tour around the premises of the primary school in addition to experiencing the "recess" with first graders. For this activity, the PT alongside the researcher, planned and facilitated a project-based activity in the preschool 
classroom -prior to this visit- where the nutritionist was also involved to help preschoolers prepare their "lunch" for their visit.

C) Third visit: preschoolers visited one first grade-classroom and carried out activities with the first-grade teacher and first graders. First graders shared their chairs with preschoolers so they can be seated for the activities prepared by the teacher. The teacher facilitated an "ice-breaking" activity for preschoolers to feel welcomed in addition to the central activity focused on the recognition of numbers, alphabet letters and the production of drawings. First graders also showed preschoolers, the classroom materials such as classroom rules, science experiments, books, maps, and so on. Preschoolers worked together with first graders who lent their colouring pencils, books, notebooks and white sheets to preschoolers to carry out the activity. First graders gave preschoolers a "present" once the visit had finished -which had been prepared in advanced.

School-School Links (First grade teachers visiting preschool classroom): Three different first grade teachers visited the preschool classroom (i.e., experimental group) in three different occasions to share their experience with preschoolers transitioning to first grade. First grade teachers highlighted the main differences between the preschool and primary school. Preschoolers were encouraged to ask questions about the primary school which were answered and clarified by first grade teachers. After every activity related to home-school and school-school bridging (Malsch, Green \& Korhari, 2010), preschool teacher facilitated an activity whereby preschoolers were asked to draw what they "saw", "hear" and "lived" not only during the visits to the primary school, but also during the first grade teachers' visits. Preschoolers shared their drawings with their peers and their parents in an "open-doors" activity organised by the preschool teacher.

\section{Data Analysis}

Descriptive statistics were obtained from the children's and teachers' measures. The Wilcoxon singed ranks two-tailed test was computed to determine differences between the paired ratings of children's and PT/TAS from pre/post-test. This non-parametric test was considered since it allows to identify differences in Likert-type scale measurements in pre-post designs taking into account the magnitude and direction of differences (Haslam \& McGarty, 2014). In order to obtain magnitude and differences in scores obtained, all analyses were conducted at $p<.05$ significance level. The Mann-Whitney $U$ test was computed to compare the scores obtained in the pre-tests from the control and experimental groups for both, to establish a baseline before the intervention took place. A thematic analysis as suggested by Braun and Clarke (2006) was carried out to analyse parents' answers.

Diólo fos 


\section{Results}

\section{Preschoolers' Skills}

Descriptive statistics. Descriptive statistics were obtained to show the means and standard deviations of the control and experimental group (Table 1), which revealed that pre-test means scores in both groups were similar prior to the intervention. Both groups of children's scores were assessed with Mann-Whitney $U$ test (Table 2 ) in terms of equivalence before the intervention since this test has been described as appropriate for use with small samples (Curtis \& Marascuilo, 2004). The sum of the ranks for each group is calculated and then compared with that of the other group. A significant $p$ value $(p<.05)$ indicates a significant difference between the two groups. Experimental and control groups did not differ in cognitive $(M=1.30, S D=.923$; $M=1.05, S D=.999)$, social $(M=1.60, S D=.754 ; M=1.45, S D=.826)$, and motor skills $(M=1.60, S D=$ $.681 ; M=1.55, S D=.759)$, respectively, $p>05$. Therefore, both groups were similar in these skills before the intervention suggesting that participants shared a similar development of cognitive, social and motor skills.

Table 1. Descriptive Statistics of Children Skills for Both Groups

\begin{tabular}{|c|c|c|c|c|c|c|c|c|c|c|c|c|}
\hline & \multicolumn{6}{|c|}{ Control Group } & \multicolumn{6}{|c|}{ Experimental Group } \\
\hline & \multicolumn{3}{|c|}{ Pre-test } & \multicolumn{3}{|c|}{ Post-Test } & \multicolumn{3}{|c|}{ Pre-test } & \multicolumn{3}{|c|}{ Post-Test } \\
\hline & $N$ & Mean & $S D$ & $N$ & Mean & $S D$ & $N$ & Mean & $S D$ & $N$ & Mean & $S D$ \\
\hline Cognitive & & & & & & & & & & & & \\
\hline Skills & 20 & 1.05 & .999 & 20 & 1.20 & .951 & 20 & 1.30 & .923 & 20 & 1.75 & .444 \\
\hline Social Skills & 20 & 1.45 & .826 & 20 & 1.60 & .681 & 20 & 1.60 & .754 & 20 & 1.90 & .308 \\
\hline Motor Skills & 20 & 1.55 & .759 & 20 & 1.55 & .759 & 20 & 1.60 & .681 & 20 & 1.85 & .366 \\
\hline
\end{tabular}

Table 2. Mann-Whitney U Test Computed with Pre-tests in Control and Experimental Group

\begin{tabular}{lllllll}
\hline & $\begin{array}{l}\text { Cognitive } \\
\text { Skills Pre-test }\end{array}$ & $\begin{array}{l}\text { Social Skills } \\
\text { Pre-test }\end{array}$ & $\begin{array}{l}\text { Motor } \\
\text { Skills Pre- } \\
\text { test }\end{array}$ & $\begin{array}{l}\text { Cognitive } \\
\text { Skills Pos- } \\
\text { test }\end{array}$ & $\begin{array}{l}\text { Social Skills } \\
\text { Pos-test }\end{array}$ & $\begin{array}{l}\text { Mo- } \\
\text { tor-Skills } \\
\text { Post-test }\end{array}$ \\
\hline Mann-Whitney U & 174.000 & 180.500 & 197.000 & 142.500 & 191.000 & 165.500 \\
Wilcoxon W & 384.000 & 390.500 & 407.000 & 352.500 & 401.000 & 375.500 \\
Z & -.796 & -.654 & -.101 & -1.839 & -.311 & -1.281 \\
Asymp. Sig. (2-tailed) & .426 & .513 & .920 & .066 & .756 & .200 \\
Exact Sig. [2*(1-tailed & $.495^{\mathrm{b}}$ & $.602^{\mathrm{b}}$ & $.947^{\mathrm{b}}$ & $.121^{\mathrm{b}}$ & $.820^{\mathrm{b}}$ & $.355^{\mathrm{b}}$ \\
Sig.)] & & & & & & \\
\hline
\end{tabular}


To analyse the effect of the intervention in the experimental group, the non-parametric Wilcoxon rank sum test (Coolican, 2009) was computed in both groups to explore statistical differences in scores (Table 3). The statistical significant difference was at the $p<.05$ level in all domains in the experimental group as shown in Table 3. As can be observed, the experimental group increased cognitive $(M=1.75, S D=.444), W=.007, p<.05$, social $(M=1.90, S D=.308), W=$ $.034, p<.05$, and motor skills $(M=1.85, S D=.366), W=.025, p<.05$. However, the control group did not improve these skills on the cognitive $(M=1.20, S D=.951), W=.083, p=.05$, social $(M=1.60$, $S D=.681), W=.083, p=.05$, and motor measures $(M=1.55, S D=.759), W=1.000, p=.05$. As hypothesised, statistical significant differences in the experimental group were found between the pre-test and post-test suggesting that the intervention program did have an effect in the development of children's skills.

Table 3. Comparison of Pre-and Post-Tests Means Scores in both Groups using the Wilcoxon Rank Sum Test

\begin{tabular}{|c|c|c|c|c|c|c|}
\hline & \multicolumn{3}{|c|}{ Control Group } & \multicolumn{3}{|c|}{ Experimental Group } \\
\hline & $\begin{array}{l}\text { Cognitive } \\
\text { Skills }\end{array}$ & Social Skills & Motor Skills & $\begin{array}{l}\text { Cognitive } \\
\text { Skills }\end{array}$ & $\begin{array}{l}\text { Social } \\
\text { Skills }\end{array}$ & $\begin{array}{l}\text { Motor } \\
\text { Skills }\end{array}$ \\
\hline Z & $-1.732^{\mathrm{b}}$ & $-1.732^{b}$ & $.000^{c}$ & $-2.714^{b}$ & $-2.121^{b}$ & $-2.236^{b}$ \\
\hline $\begin{array}{l}\text { Asymp. Sig. } \\
\text { (2-tailed) }\end{array}$ & .083 & .083 & 1.000 & $.007^{*}$ & $.034 *$ & $.025^{*}$ \\
\hline
\end{tabular}

\section{Teachers and Teaching Assistants'Transition Practices}

Preschool teachers and TAS were asked to rate the use of transition practices in preparation for the transition to first grade based on a 3-point Likert-type scale with 40-items. Descriptive statistics for teachers and TA for both groups are shown in Table 4. Additionally, the non-parametric Wilcoxon rank sum test was computed in order to analyse the differences in the means scores after the period of intervention in both groups (Table 5). Results indicated statistical significant differences between the pre-test and post-test in the experimental group; Teacher $(M=1.73$, $S D=.506) W=.000, p<.001$; teaching assistant $(M=1.55, S D=.714) W=.000, p<.001$, but no in the control group; teacher $(M=.53, S D=.877) W=1.000, p=.05$; teaching assistant $(M=.40, S D=.778)$ $W=.157, p=.05$ respectively. These results suggest that the preschool teacher and the teaching assistant of the experimental group reported a more frequent use of transition practices that promote literacy-related skills in children. 
Table 4. Descriptive Statistics for Teachers and Teaching Assistants from Both Groups

\begin{tabular}{|c|c|c|c|c|c|c|c|c|}
\hline & \multicolumn{4}{|c|}{ Pre-test } & \multicolumn{4}{|c|}{ Post-test } \\
\hline & \multicolumn{2}{|c|}{ Teacher } & \multicolumn{2}{|c|}{$\begin{array}{l}\text { Teaching Assis- } \\
\text { tant }\end{array}$} & \multicolumn{2}{|c|}{ Teacher } & \multicolumn{2}{|c|}{$\begin{array}{l}\text { Teaching Assis- } \\
\text { tant }\end{array}$} \\
\hline & Mean & SD & Mean & SD & Mean & SD & Mean & SD \\
\hline $\begin{array}{l}\text { Control } \\
\text { Group }\end{array}$ & .53 & .877 & .40 & .778 & .53 & .816 & .45 & .783 \\
\hline $\begin{array}{l}\text { Experimental } \\
\text { Group }\end{array}$ & .40 & .810 & .43 & .712 & 1.73 & .506 & 1.55 & .714 \\
\hline
\end{tabular}

Table 5. Comparison of Means Scores of Pre-test and Post-test in both Groups of Teachers by using Wilcoxon Test

\begin{tabular}{lllll}
\hline & \multicolumn{2}{l}{ Control Group } & \multicolumn{2}{l}{ Experimental Group } \\
\cline { 2 - 5 } & Preschool & Teaching As- & Preschool & Teaching \\
& Teacher & sistant & Teacher & Assistant \\
\cline { 2 - 5 } Z & $.000^{\mathrm{b}}$ & $-1.414^{\mathrm{c}}$ & $-5.097^{\mathrm{c}}$ & $-4.930^{\mathrm{c}}$ \\
Asymp, Sig. (2-tailed) & 1.000 & .157 & $.000^{* *}$ & $.000^{* *}$ \\
\hline
\end{tabular}

a. Wilcoxon Signed Ranks Test

b. The sum of negative ranks equals the sum of positive ranks

c. Based on negative ranks

$* *$ Results of the Wilcoxon signed ranks test significant at the $p<.01$ level

\section{Parents' Perspectives to Open-Ended Questions}

Parents perspectives were gathered by using three open-ended questions and analysed following a thematic analysis (Braun \& Clarke, 2006), which lead to the identification of key themes. Participants' answers were read thoroughly at least three times by the researcher to gain a fully understanding of the way in which codes would emerge. Once codes and themes were identified, two external experts in preschool education, independently reviewed the codes and themes generated by the main researcher to reach an agreement and thus enhance the trustworthiness of the results. A consensual agreement was reached for the final version of the five themes identified. Regarding the question related to the factors parents have considered in order to choose the primary school to which their children will attend, two main themes emerged from participants' answers:

School Quality. Parents mainly considered the quality of the primary school in terms of academic achievement. This is to say, they reported to having asked directly to schools and/or rely 
on what acquaintances told them regarding whether a primary school was good or bad considering the academic level. Parents highlighted "...I mainly focus on whether the school has good reputation or not. If my neighbours say that they do not have smart students, then I will not choose it..." whilst others emphasised the information given by their family members "... my brother in law had his kids in that school and they obtained high grades. I will enrol my kid in that school because it has a good academic level".

School close to Workplace. Parents emphasised that how close school was to their workplace, was an important factor to consider when choosing the primary school. Some parents mentioned: "I have found a primary school right on the back of the building where I work and that will be the school where my daughter will attend to because we can then get home together and quick". Other parents pointed out that given that the city is very big, they cannot spend hours in the traffic jam to pick their children from the primary school "I have heard about a good school close to my friend's house, however I am enrolling him in a school which is two blocks away from my workplace, otherwise it will take me two hours to pick him up". "This city is crazy and you cannot spend one and a half hours in the traffic jam. There is a school close to my house which is not a very good one, but what can I do?"

As for the second question regarding the way in which they support their child for this transition, one key theme emerged from parents' answers:

Sending Children to a "Real" School to Learn how to Read and Write. Parents reported to be concerned about their children's lack of academic skills during the preschool-academic year, which will be essential once they enter the primary school. As a result, one of the main ways in which they support their children was sending them to a "real school" because they teach children how to read and write. "I have enrolled my child in a good school where they focus on teaching children how to read and write". Other parents also pointed out that they support their children by teaching them how to read and write, "... at home, I spend two hours with my child teaching her the letters and numbers. We have even started to write words and his name". Other parents thought that a good way to prepare their child was by sending him/her to language schools: "I am concerned about the primary school and therefore my child is learning English language in a private school so he can be prepared for the primary school". Parents also thought that the current preschool centre was not good enough and therefore, they send their child to private schools:"well you know... in this school they [children] just play and do not learn anything. In April, my child will attend to a private school instead of this one so he can learn how to read and write".

Finally, parents shared what they have been talking about with their child in order to prepare them for the primary school focusing on two main themes:

New rules and obedience. Parents highlighted that the main issues they talk about leaving the preschool and entering primary school, was the need to follow teachers' directions and 
obey the new rules: "I have told my boy that he will have to behave and do whatever his teacher will tell him. He cannot play anymore and must behave well". Another parent mentioned: "...you know, mi child likes playing and talking to her peers, however, she will not be able to do that anymore. She must focus on the academic tasks the teacher requires her to do. She must be very obedient". Another parent, highlighted the challenges that this change brings to her child: "My son is very mischievous and therefore he will struggle behaving in the new school. I am teaching him that he must follow the rules and obey his new teacher or he will have problems with $\mathrm{me}^{\prime \prime}$

The need to do the "Homework". Parents reported to be aware of the differences between preschool and primary school and thus focused on the need for their child to complete everyday homework: "I have told my child that in the primary school she will have to finish every task required by her teacher. At home, she will not play until she finishes her homework". Other parents highlighted that having "homework" form the primary school will also require them to spend additional time with their child: "In primary school my daughter will do lots of homework and I will have to spend more time helping her. I have told her that she must be fast to finish whatever she is asked to do". Finally, parents also thought that learning a new language will help in their child in this transition:"... his English language homework is making him aware of the importance of doing homework. I tell my son that he will have to do both homework(s) [English language and Primary school] if he wants to play XBox"

\section{Parents'S Parents' Satisfaction}

Twenty parents who participated in the preschool transition-intervention programme, completed the satisfaction survey at the end of the intervention. Mean scores were computed and revealed that based on a 5-point scale, $95 \%$ (19) of parents felt very satisfied ( $M=4.95 S D=0.22$ ) with the intervention programme.

\section{Discussion}

Overall, findings provide evidence of the positive impact of the preschool transition-intervention programme on children's cognitive, social and fine motor skills as well as in the frequency with which PT and the TA, use transition practices that promote literacy in preparation to the transition to first grade. Parents reported that the quality of the primary school and closeness of the school, were the main factors to consider when choosing the primary school to which their child will attend. Parents reported that promoting academic skills in their child is essential to prepare them for this transition. Following rules and being obedient were the main topics on which parents mainly focused when talking with their preschool child about the primary school, also reporting to being very satisfied with the implementation of the programme. This intervention was research-informed, being the first of its kind to be implemented in a Latin American context since most of the preschool transition research has been carried out in developed economies such as Australia, Iceland, UK, Italy, Greece and US. 
Results revealed statistical significant differences in children' skills after the intervention programme in the experimental group, suggesting that children benefited from the various activities implemented throughout the intervention, however caution must be taken when interpreting the results since there could be a number of confounding variables influencing these results. Findings from this study, confirm the usefulness of a range of activities which can be implemented in preschool classrooms to help pre-schoolers develop cognitive, social and fine-motor skills grounded on a collaborative work between preschool teachers, teaching assistants and parents -which is indeed, very much in line with some of the principles of the the Ecological and Dynamic Model of Transition (Rimm-Kauffman \& Pianta, 2000). Modelling key developmental aspects and transition practices (i.e., new knowledge for teachers), improving classroom-areas, implementing literacy-related activities and promoting visits to the primary school-considering the socio-cultural context and curriculum-, seemed to be an effective strategy to support teachers and parents acquire new knowledge and develop practices to support pre-schoolers during this transition. These results are consistent with previous studies (Berlin, Dunning \& Dodge, 2011; Brotherson et al., 2015) which have shown significant effects of interventions in children's skills. Moreover, significant improvements in children's skills have also been observed in large-scale studies where a number of transition practices had also been implemented by teachers (Schulting, Malone \& Dodge, 2005). Whilst the lack of a randomised allocation of preschoolers in the experimental and control group could represent a limitation in the present study, statistical analyses still revealed a positive impact in the development of children's skills. Nevertheless, other factors such as children's extra-curricular activities, number of older siblings at home, etc. were not controlled. Future studies should consider a randomised allocation of participants for both groups. Whilst results suggest that children in the experimental group developed more skills after the intervention, this study did not follow up pre-schoolers during the first year of primary school which could have allowed to explore the long-term effect of this intervention. Future studies should focus on a more rigorous experimental and longitudinal design to be able to investigate the long-term impact of transition interventions. Furthermore, skills developed by children must be further analysed to understand whether they contribute to a smooth transition to the first grade classroom.

This intervention helped preschool teacher and TA significantly improve the use of transition practices. Whilst these transition practices showed to be relevant to support the development of cognitive, social and fine motor skills in children, there is the need to focus on additional developmental domains (i.e., emotional). Although this intervention showed positive outcomes with teachers, other confounding variables (e.g., peer-to-peer support, exchange of ideas with other teachers, etc.) could have had an impact on teachers which were not controlled and which need to be considered in future research. 
Teachers seemed to have promoted an important parental involvement which has also been observed in other studies as a result of interventions (Stormshak, Kiminski \& Goodman, 2002). Whilst family involvement was not measured in this study, it was clear that parents' engagement in classroom activities provided preschoolers with joyful experiences by seeing their parents coming to their classroom. Findings from family engagement activities in this study, are similar to those in found previous studies (Wildenger \& Mclntyre, 2011). This intervention helped the preschool teacher and TA carry out helpful activities (Dockett \& Perry, 2007; Stormshak, Kaminski \& Goodman, 2002) to promote school-school links. However, future research is needed to explore the prevalence of such practices in teachers' repertoire. The constant teacherparents' interactions and visits to the primary school, (i.e., "bridging"), led to a more frequent exchange of information among adults, which also allowed preschoolers to finally get to see -in a concrete way- what a primary school looked like.

Parents seemed to be aware of the differences between the preschool and primary school, however they mainly focus on their child's academic skills leaving out other aspects (i.e., social, emotional, etc.). This is not surprising since previous studies have shown that parents usually consider early literacy skill as essential to start first grade (Lee \& Goh, 2012), given that one of the key aspect of this transition is the change to a more academic-led curriculum suggesting a "curriculum discontinuity" (Turunen \& Maatta, 2012). As a results parents' main supporting strategies, focused on helping their child learn how to read and write. Parents believed that enrolling their child in "real schools" -where they will learn how to read -in addition to learning another language (i.e., English), was essential. Similarly, parents reported that the main issues they focus on when talking to their child about their imminent entry to primary school were following new rules, carrying out classroom activities as required, doing homework and being obedient which is consistent with previous findings (Chun, 2003; Fabian \& Dunlop, 2005). Parents also reported how these "new challenges" would have an impact on their daily routine since they would have to spend more hours with their child helping him/her with the "homework" which is consistent with other studies where a change in parents' routines has been importantly highlighted (Margetts \& Kienig, 2013). Interestingly, parents' main criteria for choosing the primary school focused on school's academic level and closeness to parents' workplace.

To sum, this study has addressed an important gap in the literature whereby most of the preschool transition has been carried out in developed economies such as Australia, Iceland, US and broadly Europe, overlooking developing economies such as those found in Latin America. Worryingly, this region has shown one of the lowest academic performance based on international assessment exercises (OECD, 2012), and yet, little is known as to the way in which their context, cultural practices, values, educational policies, curriculum, etc. shape the preschool transition. This study represents one of the first attempts to explore a specific and adapted intervention programme to aid the preschool transition including teachers, TAS, children and 
parents in a single intervention. This study adds to the international literature, by providing empirical evidence regarding the implementation of a transition intervention in a developing economy such as Mexico, contributing to what is already known from developed economies. Findings suggests that by implementing intervention programmes of this nature, significant improvement can be observed in pre-schoolers' skills, teachers' practices and parents' involvement which could facilitate pre-schooler's transition to first grade. These findings, must be replicated in order to broaden the extent to which these results can be generalised to other developing economies. We encourage the implementation of this type of interventions in similar contexts with a view to gathering empirical evidence which could inform educational policies in near future.

\section{Reference List}

Berlin, L. J.; R. D. Dunning; K. A. Dodge(2011). Enhancing the transition to kindergarten: A randomized trial to test the efficacy of the "Stars" summer kindergarten orientation program. Early childhood research quarterly, 26(2), 247-254.

Braun, V. y Clarke, V. (2006). Using Thematic analysis in psychology. Qualitative

Research in Psychology, 3(2), 77-101.

Bricker, D.; K. Pretti-Frontnczak (2002). Assessment, Evaluation, and Programming System for Infants and Children (AEPS ${ }^{\oplus}$ ), Second Edition, Administration Guide. (AEPS). USA: Paul H. Brookes Publishing Co.

Brownell, M. T.; E. Yeager; M. S. Rennells; T. Riley (1997). Teachers working together: What teacher educators and researchers should know. Teacher Education and Special Education: The Journal of the Teacher Education Division of the Council for Exceptional Children, 20(4), 340-359.

Carida, H. C. (2011). Planning and implementing an educational program for the smooth transition from kindergarten to primary school: The Greek project in all-day kindergartens. The Curriculum Journal, 22(1), 77-92.

Chun, W. N. (2003). A study of children's difficulties in transition to school in Hong Kong. Early Child Development and Care, 173(1), 83-96.

Claes, B. (2010). Transition to Kindergarten: the impact of preschool on kindergarten adjustment. (Doctoral Dissertation). Recuperado de ProQuest. Dissertation Abstracts International Section $A, 71,1902$.

Coolican, H. (2009). Research Methods and Statistics in Psychology (Quinta edición). Londres: Hodder Education, Hachette Reino Unido.

Cox, M. LaParo, K.; R. Pianta (2000) Teachers' reported transition practices for children transitioning into kindergarten and primer grade. Exceptional Children, 67(1), 7-20. 
Curtis, D. A. y Marascuilo, L. A. (2004). Point estimates and confidence intervals for the parameters of the two-sample and matched pair combined test for ranks and normal scores. Journal of Experimental Education, (60), 243-269.

Dockett, S.; B. Perry (2007). Transitions to school: Perceptions, expectations, experiences. UNSW Press.

Dockett, S.; B. Perry (2013). Trends and tensions: Australian and international research and starting school. International Journal of Early Years Education, 21(2), 163-177. DOI: 10.1080/ 09669760.2013 .832943

Fabian, H. y Dunlop, W. (2005). 'The Importance of Play in the Transition to School'. En Moyles, J. R. (ed.). The Excellence of Play, Segunda edición. Berkshire: Open University Press/McGraw-Hill.

Fabian, H.; A. W. Dunlop (2007). Outcomes of Good Practice in Transition Processes for Children Entering Primary School. Working Papers in Early Childhood Development, (42). Bernard van Leer Foundation. PO Box 82334, 2508 EH, La Haya, Holanda.

Giallo, R.; K. Treyvaud; J. Matthews; M. Kienhuis (2010). Making the transition to primary school: An evaluation for a transition program for parents. Australian Journal of Education \& Developmental Psychology, (10), 1-17.

Hart, K. C. (2012). Promoting Successful Transitions to Kindergarten: An early Intervention for Behaviourally at Risk Children from head Start Presschools. (Disertación Doctoral). ProQuest.

Haslam, S. A.; C. McGarty (2014). Research methods and statistics in psychology. Sage.

Hedegaard, M.; M. Fleer (2013). Play, Learning, and Children's Development: Everyday Life in Families and Transition to School. Cambridge: Cambridge University Press.

Kagan, S. L.; K. Tarrant (2010). Transitions for Young Children: Creating Connections across Early Childhood Systems. Baltimore: Brookes Publishing Co.

Kerlinger, F. N. 1986 Foundations of Behaviour Research. Nueva York: Holt, Rinehart and Winston.

Ladd, G. W., Buhs, E. S. y Seid, M. (2000). Children's initial sentiments about kindergarten: Is school liking an antecedent of early classroom participation and achievement? Merrill-Palmer Quarterly (1982-), 255-279.

Lee, S.; G. Gogh (2012). Action Research to Address the Transition to Kindergarten to Primary School: Children's Authentic Learning, Construction Play and Pretend Play. Early Childhood Research and Practice, 14(1).

Li, H. C. W.; Y. W. Mak; S. S. Chan; A. K. Chu; E. Y. Lee; T. H. Lam (2013). Effectiveness of a playintegrated primary one preparatory program to enhance a smooth transition for children. Journal of health psychology. https://doi.org/10.1177/1359105311434052

LoCasale-Crouch, J.; A. J. Mashburn; J. T. Downer; R. C. Pianta (2008). Pre-kindergarten teachers' use of transition practices and children's adjustment to kindergarten. Early Childhood Research Quarterly, 23(1), 124-139. http://doi:10.1016/j.ecresq.2007.06.001 
Loughran, J. J. (2002). Developing reflective practice: Learning about teaching and learning through modelling. Routledge.

Margetts, K.; A. Kienig (2013). International perspectives on transition to school: reconceptualising beliefs, policy and practice. Routledge.

Malsch, A. M.; B. I. Green; B. H. Kothari (2011). Understanding parents' perspectives on the transition to kindergarten: What early childhood settings and schools can do for At-risk families. Best Practice in Mental Health, 7(1), 47-66.

Miller, K. (2015). The Transition to Kindergarten: How Families from Lower-Income Backgrounds Experienced the First Year. Early Childhood Education Journal, 43(3), 213-221.

Neuman, S.B.; S. Bredekamp; C. Copple (2000). Learning to read and write: Developmentally appropriate practice. Washington: NAEYC

OECD (2012). Education at a Glance 2012: Highlights. París: OECD.

Perry, B.; S. Dockett; A. Petriwskyj (2014). Transitions to school-international research, policy and practice. Nueva York: Springer.

Pianta, R. C.; M. Kraft-Sayre; S. Rimm-Kaufman; N. Gercke; T. Higgins (2001). Collaboration in building partnerships between families and schools: The National Center for Early Development and Learning's Kindergarten Transition Intervention. Early Childhood Research Quarterly, 16(1), 117-132.

Pierce, C. D.; D. A. Bruns (2013). Aligning components of Recognition and Response and Response to Intervention to improve transition to primary school. Early Childhood Education Journal, 41(5), 347-354.

Rathbun, A. H.; E. G. Hausken (2001). How Are Transition-to-Kindergarten Activities Associated with Parent Involvement during Kindergarten?

Rimm-Kauffman, S., Pianta, R. y Cox, M. (2000). Teachers' Judgements Problems in the Transition to Kindergarten. Early Childhood Research Quarterly, 15(2), 147-166.

Sassen, S. (2011). Cities in a world economy. Sage Publications.

Silberman, M. (1996). Active Learning: 101 Strategies To Teach Any Subject. Prentice-Hall, PO Box 11071, Des Moines, IA 50336-1071.

Stormshak, E. A.; R. A. Kaminski; M. R. Goodman (2002). Enhancing the parenting skills of Head Start families during the transition to kindergarten. Prevention Science, 3(3), 223-234.

Stormont, M.; R. Beckner; B. Mitchell; M. Richter (2005). Supporting successful transition to kindergarten: General challenges and specific implications for students with problem behavior. Psychology in the Schools,42(8), 765-778.

Taylor, S. J.; R. Bogdan; M. DeVault (2015). Introduction to qualitative research methods: A guidebook and resource. John Wiley \& Sons.

Toohey, K.; E. Day (2001). Home to School/Kindergarten to Grade 1: Incommensurable Practises? 
Turunen, A. y Maatta, K. (2012) What constitutes the pre-school curricula? Discourses of core curricula for pre-school education in Finland in 1972-2000. European Early Childhood Education Research Journal, 20(2), 205-2015

Wildenger, L.; I. Mclntyre (2011). Family concerns and involvement during kindergarten transition. Journal of Child and families studies. 20, 387-396. 